\title{
Library buildings in a digital age, why bother?
}

\section{Defending new library buildings and additions to college administrators and trustees}

by Alice Harrison Bahr

$\mathrm{T}$ he earnest predictions of the 1980 s and early 1990s "that libraries would become superfluous-mausoleums for books-when so much was available online" hasn't come to pass, according to David L. Marcus. In fact, writes Marcus, "Library visits now far exceed annual attendance at sporting events, concerts, and museums combined."

Many prestigious educational institutions have completed new library build ings. They include, among many others, Loyola University (Louisiana), Oregon State University, Fordham University (New York), Eastern Michigan University, University of Kentucky, Florida International University, Marshall University (West Virginia), Samford University (Alabama), Augsburg College (Minnesota), Bellarmine College (Kentucky), and Wayne State University (Michigan).

Here are ten points to make to your administrators when proposing a new library or addition:

1. Libraries have new functions in a digital age. Quoting Jerorld Orne, past compiler of Library Journats construction surveys, respected library building consultant Nancy McAdams emphasizes that ". . . the new concepts ... [applied to building modern libraries are]... service concepts-li- brary as learning center, library as information utility, the sharing of resources, all working together to change the emphasis from collection space to user space." 2 Most newly constructed libraries continue to provide shelving for books, but they also include space for networked conference rooms, electronic presentation rooms, lounge seating with Internet connections, electronic classrooms, faculty/student technology development spaces, collaborative work and study spaces, teleconferencing spaces, and 24-hour cafes, computer labs, and group study rooms.

2. New library buildings and additions can shore up an institution's aging technological infrastructure. For many institutions, constructing a new library provides a means of both meeting a myriad of academic needs and updating a campus's technologies. Instead of trying to distribute videoconferencing and distance education facilities throughout a campus, institutions can centralize them in the library, making the library the electronic hub of the campus.

3. Libraries continue to be retreats from the world. Another well-known library building consultant, Jay Lucker, who helped develop the Massachusetts Institute of Technology's (MIT) strategic plan, has written, "At the beginning of the 21 st century, 
the MIT libraries as buildings housing physical collections with convenient spaces for users to consult these collections will continue to be important. . . The Libraries will continue to be a place for self-education and discovery outsicle the classroom and laboratory; they will continue to be a haven from the pressure of academic life and communal living. They will be a place of particular importance to students, as part of the social and intellectual experience of an MIT education.".3

4. Everything will not be going digital. The lure of libraries with state-of-the-art technology, high-speed backbones that can bring video to the desktop, and electronic presentation, teleconferencing, and conference rooms will not render books obsolete. Futurists and teclunologists are clear on this matter. The issues are cost, reliatbility, and politics.

First there is the publisher's/organization's cost to convert print to digital formats. Walt Crawford answers the question, When will all existing library materials be converted to digital form? with: "Not in my lifetime, probably not in yours, and quite likely never." Although the Library of Congress's and research libraries digitizing of nonprint and brittle materials "will yield cligital collections that enhance and extend libraries. . . . They will not yield alldigital libraries. . . . The Library of Congress continues to acquire new print materials much faster than it digitizes old ones. If anyone has universal conversion as a goal-which I cloubt-we're moving backwards."

\section{The cost of a completely digital library} is prohibitive. According to Crawford, the cost of converting libraries to completely digitized formats is too expensive and the rewards keep diminishing ${ }^{6}$ More often than not, electronic files are more expensive than their print counterparts, and Web access is more expensive than CD-ROM. No library can afford all available or developing electronic services. The increasingly digital library is increasingly expensive. As Peter Lyman, university librarian and professor in the School of Information Management and Systems at Berkeley writes: "Nor is there evidence that the digitized library is cheaper, given the cost of technology and the necessity to invest continuously in new technology."7

The cost issue, along with preservation and reliability, have other implications, as well. spring Hill College's Library now subscribes to several online indexes and full-text journal databases. The library doesn't own this information. It pays to access it. If the companies providing the information go out of business or raise prices exorbitantly, the library has no physical copy of these journals and hooks and it loses that information. In the past, litoraries paid for a journal or a book and, barring fire or other mishap, the information was theirs permanently.

\section{Electronic storage may not be reliable.} Richard Bazillion and Connie Braun point out that "entrusting the scholarly record to volatile electronic storage in fact may endanger it."

7. The courts are still battling ownership issues in a digital age. Music and data may be on the Internet and in some cases access may be free, but that doesn't mean that material may be copied at will at no cost.

8. Most technologists agree that reading books on a computer is unsatisfying. It is rarely as comfortable as flipping, and writing on the pages of a book. Bill Gates himself acknowledged in a speech at Harvard that "even at Microsoft. when a document runs to three or four screens, people tend to print it out rather than read and use it in al digitized form. .".

9. There are deficiencies in many programs to contend with. As Library Director Marilyn Gell Mason suggests. "The written word sparks images and evokes metaphors that get much of their meaning from the reader's imagination and experiences. When you read a novel, much of the color, souncl, and motion come from you. ${ }^{10}$ Even revolutionary guru Nicholas Negroponte confesses: "Interactive multimedia leaves very little to the imagination.

10. Books and libraries provide contexts. As Marilyn Gell Mason points out, a printed document is essentially different from an electronic one.

With a print volume, "As you read, you are aware of how much has come before and how much is yet to be cliscovered. That

provides a context for an instant message, a frame that helps to understand where you are in relation to the material at hand. This context provides its own value system. . . In a hypertext world where you are propelled by your mouse from one screen to another, these contexts disappear.

(continued on page 608) 


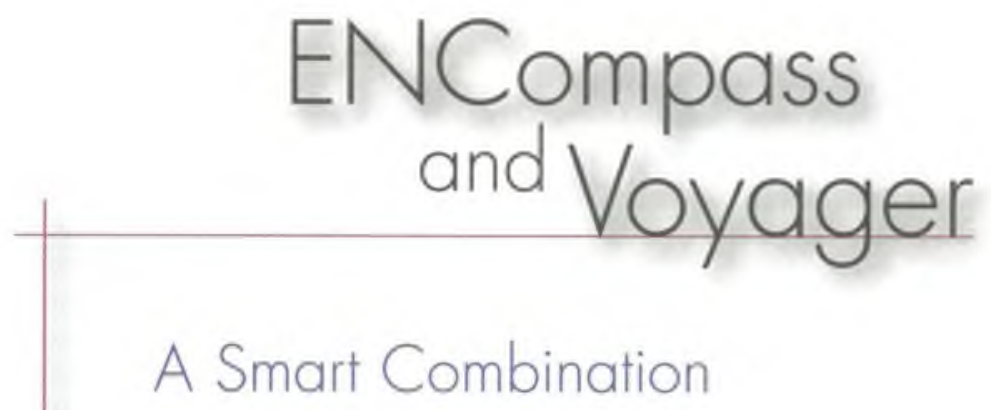

en[compass]. First. Voyager gave you integraled management copabilities for your library's peint collection. Now Endeavor Information Systems inc introduces ENCompass - the neat step in soltware for the electronic world. Created for today's digital library, ENCompass takes advantage of new technology and standards llike XML, EAD, and Dublin Core) 10 describe, index and search a variety of electronic resources. Smartly designed to work in tandem with Voyoget, ENCompass lets you integrate all of your resources, no matter what their localion. Digital or print - now your users can have it all.

\section{Endeavor}

Sman Design. Solid Decision. 


\section{Equalize the benefits for the theorist and the practitioner, and let each do the job he or she does best.}

Many academic libraries have placed such an emphasis on publishing that all new librarians are enrolled in committees in which topics for research are suggested, various avenues to publication are recommended, and encouragement, if not enthusiasm, is sustained by personal success stories; more time away from the work.

Publication is, and has been. useful, but it need not be mandatory. Librarians are just as valuable because of their technical skills, subject specialties, and ability to mediate between the classroom and the collection. When a student or professor seeks assistance from a librarian, he or she has no interest in whether that librarian has published; what is required is someone who listens well and is able to translate a frequently ambiguous or garbled need into a structured search of a database or of a collection that has been assiduously developed, monitored, and cataloged.

In a world of overspecialization, librarians may still be generalists (as opposed to the narrower and slicker term "information specialist"). They are then invaluable as mediators between the humble student or the prestigious professor and the worldwide collection of information (as opposed to "data").

I believe we are about to experience a revolution in which the classroom teacher and the "library's librarian" will achieve equal appreciation in every sense from the administration and from their peers. Equalize the benefits for the theorist and the practitioner, and let each do the job he or she does best.

\section{Notes}

1. Alan Edelson, "Re: Electronic availability," message to Liblicense-L Discussion List at liblicense-l@lists.yale.edu on October 14, 1999. Archived at http://www.library.yale. edu/ llicense/ListArchives/9910/msg00017. html.

2. Zachary Karabell. What's College for? The Struggle to Define American Higher Education (New York: Basic Books, 1998).
("Library'buildings .. "continued from page 591)

If a book provides contexts, so do libraries. Their existence provides a sense of past and present and implies that "there is more to the study of philosophy than a book by Kant, more to the study of science than an article on geophysics. . . By their space and substance they provide a sensory understanding that knowledge is broader than any one subject field. . . . It is this sensory understanding that we often forget when we discuss information. Humans are more than a collection of electrical impulses.

"Learning, knowing, takes place on many levels. . . There is something we know about knowledge when we walk in a library that we do not know when we sit at a computer terminal. "13

\section{Notes}

1. David L. Marcus "File this under shock. future," U.S. News \& World Report (July 12, 1999): 48 .
2. Nancy R. McAdams, "Trends in Academic Library Facilities," Library Trends 36, 2 (Fall 1987): 289

3. Jay K. Lucker, "Library Buildings: Their Current State and Future Development," Sci-Tech L $i$ braries of the Future 13, 1 (Fall 1992): 4 .

4. Walt Crawford, "Paper Persists: Why Physical Library Collections Still Matter." Online 22, 1 (Jan-Fel). 1998): 42-48.

5. Ibid.

6. Ibid.

7. Peter Lyman, "What is a Digital Library?" Books, Bricks, G Bytes, Daedalus (Fall 1996): 12.

8. Richard J. Bazillon and Connie Braun. Academic Libraries as High-Tech Gateways (Chicago: American Library Association, 1995): 19.

9. Marilyn Gell Mason. "The Yin and Yang of Knowing," Books, Bricks, E Bvtes, Daedalus (Fall 1996): 165.

10. Ibid., 167.

11. Ibid.

12. Ibid.

13. Ibid., 170. 